\title{
RESSALTOS, ANESTESIAS E FISSURAS: SOBRE A COSTURA COTIDIANA DE CORPOS APRISIONADOS
}

\author{
Sara Vieira Antunes ${ }^{1}$ \\ ${ }^{1}$ Programa de Pós-Graduação em Antropologia Social, \\ Universidade de São Paulo (USP), São Paulo/SP, Brasil
}

Nossa sentença não soa severa. O mandamento que o condenado infringiu é escrito no seu corpo com o rastelo. No corpo deste condenado, por exemplo - o oficial aponta para o homem -, será gravado: "Honra o teu superior!"

O explorador levantou fugazmente os olhos na direção do homem; este manteve a cabeça baixa quando o oficial apontou para ele, parecendo concentrar toda a energia da audição para ficar sabendo de alguma coisa. Mas o movimento dos seus lábios protuberantes e compridos mostrava claramente que não conseguia entender nada. O explorador queria perguntar diversas coisas, mas à vista do homem indagou apenas:

- Ele conhece a sentença?

- Não, disse o oficial, e logo quis continuar com suas explicações.

- Ele não conhece a própria sentença?

- Não - repetiu o oficial e estacou um instante, como se exigisse do explorador uma fundamentação mais detalhada da sua pergunta; depois disse:

- Seria inútil enunciá-la. Ele vai experimentá-la na própria carne.

(Kafka, Na Colônia Penal) 
Na prisão o ar é denso e pesado. Os corpos seminus daquelas/es ${ }^{1}$ que habitam as celas e os corredores contrastam com os agasalhos deixados por visitantes na sala de revista. É inútil adentrar a sequência de portões e grades portando roupas de frio - em poucos metros serão bagagem para os braços. No caminho até o Regime de Observação (RO), os corredores cinzas mais parecem tubulações. O centro dos pavilhões cercado por celas é atravessado por frestas de ar que chegam desde janelas retangulares no interior dos barracos e da única porta que leva ao espaço externo de convívio. A ausência de árvores nos pátios - dissonante em face da ostentosa arborização de seus portais - também parece corroborar a sensação abafante de seus interiores.

Shorts, bermudas, blusas cavadas e curtas predominam nos corpos que circulam no andar térreo do pavilhão do RO.$^{2}$ No castigo, ${ }^{3}$ por sua vez, roupas íntimas, top e samba-canção ainda convivem com o escorrer de gotas de suor. O interior de suas reduzidas celas intensifica o calor pela convivência acumulada de pessoas. As superfícies expostas da pele podem ser vistas com facilidade - tatuagens, escaras e hematomas comumente desenham linhas, cores e profundidade pela extensão dos diferentes corpos. É a essas marcas, inscritas no corpo e visíveis na extensão da pele ou percebidas pela alteração dos sentidos, que este artigo se dedica. Marcas costuradas na carne pela experiência cotidiana de habitar a prisão.

$* * *$

As reflexões realizadas neste artigo fazem parte da minha dissertação de mestrado, intitulada Habitar entre grades: táticas de vida no cotidiano de uma penitenciária feminina, defendida em 2017. A pesquisa foi realizada através de um projeto de leitura levado às pessoas presas no pavilhão do Regime de Observação da Penitenciária Feminina de Santana (PFS), na cidade de São Paulo, durante os anos de 2015 e 2016. As visitas, feitas por Vera e por mim, ocorriam semanalmente em função de um projeto de leitura apoiado pela Pastoral Carcerária (PCr), organização da Igreja Católica que presta assistência religiosa e jurídica a pessoas presas por todo o país. Vera e eu, igualmente agentes da Pastoral Carcerária, entrávamos às sextas-feiras por volta das $14 \mathrm{~h}$ no pavilhão do RO para dar início à oficina de leitura. Ao passar pela gaiola que conduz ao pavilhão, tínhamos nossa chegada anunciada por gritos que ecoavam pelos corredores dos três andares: pastoral, pastoral!!! Algumas pessoas aguardavam em frente ao portão/grade de entrada, outras permaneciam nos seus barracos com as portas abertas, no corredor a conversar, no pátio a tomar sol. 
Depois de passar pelo portão/grade, via-se um largo corredor que levava à escada para o primeiro andar: do lado direito, as celas do castigo e do lado esquerdo, as celas do trânsito. No segundo e último andar ficavam as celas do seguro, ${ }^{4}$ onde o silêncio e a nebulosidade imperavam - nada se escutava, nada se via e nada se sabia sobre o que acontecia no último andar. Desde a entrada do pavilhão tinha-se uma visão panorâmica de todas as celas, dispostas em forma de U, com maior facilidade em visualizar aquelas do térreo, avistando somente a parte superior das portas das celas do primeiro andar (castigo e trânsito) e uma fresta das portas do segundo andar, física e visivelmente inacessíveis.

A movimentação do RO, em comparação com os buliçosos corredores dos outros pavilhões em que eu havia entrado até então, era vagarosa. As pessoas pareciam estar a maior parte do tempo sob o efeito acachapante de remédios psiquiátricos. O andar moroso, as palavras forçadas e os movimentos dilatados produziam a especificidade do térreo, justapostos aos gritos e às conversas atravessadas pelas celas do primeiro andar do pavilhão. O ritmo no RO, mesmo com os gritos entrecortados entre castigo e trânsito, em comparação com os outros pavilhões, era qualificado pelas suas moradoras como calmo.

Jane, ${ }^{5}$ confinada há quase trinta dias numa cela do castigo, falava sobre sua profissão de tatuadora nos últimos vinte anos intermitentes de cadeia, ocasião na qual explicou sobre as gambiarras comumente desenvolvidas para tatuar dentro da prisão. Segundo ela, uma agulha de costura dentro de uma caneta bic faz minúsculos furos molhados em tinta de tecido de roupa; com maiores recursos, forjam-se tecnologias mais acuradas: uma caneta presa por um arame de caderno ou uma colher com uma extremidade acoplada a um pequeno motor (encontrado em diversos aparelhos eletrônicos), preso com fita adesiva a uma caixinha de fósforo, de um lado, e um botão, do outro; na outra extremidade, a ponta da caneta é substituída por uma fina agulha, mergulhada na tinta de tecido a cada encontro com a pele. ${ }^{6}$

Entre idas e vindas, Jane valeu-se de suas habilidades na escrita e no desenho para arrecadar maços de cigarro que sustentavam seu consumo e eram trocados por utensílios necessários ao cotidiano. Disse que se alfabetizou na cadeia, onde desenvolveu o prazer pela leitura e posteriormente pela escrita. Lá também começou a desenhar, enfeitando cartas e ensaiando rascunhos; com os anos, aperfeiçoou suas linhas e passou a desenhá-las na superfície da pele com objetos improvisados. Assim como a tatuagem, tornou-se igualmente referência na prisão por sua escrita habilidosa, atendendo à demanda pulsante de pessoas que a procuravam para transcrever suas cartas. 
Das leituras que fazia, demonstrava conhecer vastamente a literatura brasileira e era particularmente apaixonada pelas obras de Machado de Assis - dizia já ter lido tudo que ele escreveu em vida. No seu barraco guardava uma pilha de papéis com três livros que redigiu à mão sobre sua vida no cárcere. Neles, contava sobre o cotidiano truculento da prisão, seus embates com agentes da segurança penitenciária, os desejos, os anseios e as frustrações advindas do tempo passado entre grades. Escrevia poemas e contos, mas, prioritariamente, redigia relatos das vivências que tivera nos muitos anos acumulados entre idas e vindas no sistema prisional.

Na segunda vez em que a encontrei cumprindo trinta dias de isolamento nas celas do castigo, parecia especialmente angustiada e abatida. Ao indagá-la sobre o que acontecera, relatou o evento que a trouxera mais uma vez ao pote: segundo ela, na primeira batida ${ }^{7}$ feita pelos agentes do Grupo de Intervenção Rápida (GIR), ${ }^{8}$ foram encontrados carregadores e um celular na sua cela, acarretando a reclusão no castigo de duas colegas suas, que moravam naquela cela. Antes da efetiva apreensão de suas amigas pelo agente do GIR, Jane começou a confrontá-lo declamando em alto e bom som o poema de Machado de Assis chamado "O Verme":

Existe uma flor que encerra

Celeste orvalho e perfume

Plantou-a em fecunda terra

Mão benéfica de nume

Um verme asqueroso e feio

Gerado em lodo mortal,

Busca esta flor virginal

E vai dormir-lhe no seio

Morde, sangra, rasga e mina

Suga-lhe a vida e o alento

A flor o cálix inclina

[...]

Segundo Jane, ao ouvir a declamação do poema, o agente do GIR se enfureceu e começou a agredi-la por todo o percurso até o pote, onde foi deixada para cumprir falta disciplinar durante trinta dias, por "desacato e ofensa", ocasião na qual a encontrei pela primeira vez.

Poucos meses depois de ter retornado ao convívio, de volta à rotina habitual, Jane sofreu mais uma batida do GIR no pavilhão onde morava. No entanto, dessa vez, tão logo foi reconhecida pelo policial que a havia agredido da última vez, este acobertou o rosto com um capuz preto, agarrou-a pelos cabelos e arrastou seu corpo por todo o corredor até um canto onde começou 
a dar bicudas na sua costela e barriga. Contudo, a ênfase e o desespero de seu relato não estavam efetivamente nas agressões físicas que sofrera, mas no que foi feito em seguida, quando ela já estava no castigo: todos os seus manuscritos foram encontrados e destruídos. O relato exasperado de Jane pela boqueta era complementado por outras mulheres que a acompanhavam no castigo e diziam ter assistido ao episódio desde as celas e os corredores do pavilhão.

Nunca vou esquecer o olhar de ódio na cara dele. Eles parecem uns cães raivosos quando entram aqui, vão destruindo tudo, jogando as coisas no chão, quebrando, rasgando, xingando todo mundo dos palavrões mais baixos possíveis: puta, vagabunda, vadia, lixo, verme, demônio, merda, filha da puta e por aí vai... Depois que cheguei aqui no pote é que me contaram: destruíram tudo lá no barraco, inclusive a pilha de papel com todos os meus livros. Não dá pra acreditar que fizeram isso... Mas tudo bem, é isso mesmo, vai ficar tudo bem, porque eu vou refazer tudo de novo. Tá tudo aqui, oh (aponta para a cabeça). Eles podem tirar tudo de mim, podem destruir tudo, as minhas coisas, me bater, botar fogo em tudo, mas a minha mente, o meu conhecimento, eles nunca vão tirar! (Trecho retirado do caderno de campo, 23/03/2016).

Na semana seguinte ao incidente, Jane parecia mais calma. Como de praxe, eu entreguei papéis, canetas, envelope e livros que constituíam parte do projeto de leitura que levávamos ao pavilhão. Usualmente entregava algumas folhas pautadas para cada pessoa, suficientes para que pudessem escrever cartas aos familiares e recados que eram enviados de uma cela para outra. Jane, dessa vez, me solicitou uma quantidade maior que a usual, para que pudesse progressivamente retomar o penoso processo de reescrita dos seus livros. Sabia que ainda lhe restavam alargados dias de castigo à frente, então pretendia usar esse tempo para recomeçar o trabalho de escrita das folhas que contavam sua vida na cadeia e falavam justamente da perversa mecânica prisional responsável por destruir papéis, narrativas, memórias e, no limite, vidas.

No nosso próximo encontro, Jane me aguardava na boqueta da cela. Queixava-se por não ter tido tempo hábil para se concentrar na reescrita do livro: "O castigo tava uma bagunça, vários bos. ${ }^{9}$ a semana toda pra resolver não consegui ter um minuto de sossego pra escrever direito. Saiu uma folha só...". Diferentemente do que parecia acontecer no térreo do pavilhão, onde passos lentos e conversas morosas predominavam entre corpos adormecidos por psicofármacos, a rotina das celas do castigo parecia compartilhar, em parte, do frenesi de bo.s e corres dos outros pavilhões. Naquela semana, Jane dizia ter conseguido escrever apenas a abertura do livro, que intitulou Arquivo Morto, ${ }^{10}$ que transcrevo aqui: 
Oláá. Tudo bem?

Caro leitor, amigo que daqui pra frente estará comigo consumindo e absorvendo cada palavra que juntas constituirão um castelo grandioso e real, majestoso conjunto de frases que, transitando no âmago de cada um, revelará emoções com as quais um dia, mesmo eu, tive que aprender a lidar.

Você em alguns momentos se decepcionará nesses relatos, talvez eu lhe cause algum tipo de antipatia por mim, no entanto, lhe será impossível abandonar qualquer parágrafo ou página em andamento. Desculpe-me, desde já, ser categórica e realista, no entanto eu infelizmente o coloco cara a cara com um monstruoso filme de terror. Sendo assim, lhe devo o maior voto de gratidão e agradecer o quanto você foi frio(a), calculista e generoso(a) em sua dedicada atenção e entendimento na minha necessidade absurda de impor desesperada e obrigatoriamente as revelações de onde não existe um apocalipse próximo, e sim um apocalipse tão atual e presente como nossa própria existência.

Por isso existir é uma prova de onde se deve agir. Nunca omitir. Em nossos encontros emocionais de cada situação você com certeza adquirirá uma opinião clara e individual.

Lhe peço com carinho um grau de sua consciência limpa, pra que crie forças e encare tanto quanto eu, mas nunca $\mathrm{COMO}$ eu, esse fim de histórias tão tristes, nos deixando levar com coragem por esses caminhos cheios de indiferenças e desprezo que atingirá fatalmente toda sua descendência. Essa nossa geração futura será extinta se dermos as costas a ela.

Lhes falo agora como mendigo a lhe pedir a esmola, e me deem um bocadinho do seu ouvido, para que lhe segrede profecias revestidas na frieza de uma sociedade fantasiada de egressa.

Acorde!!!

Não é carnaval!

Jane, ciente da dificuldade que teria em sair da prisão com esses papéis e os relatos que eles continham, pediu que eu os levasse comigo toda semana, de modo que ela me entregaria aos poucos aquilo que conseguisse escrever nos dias de pote que ainda restavam. Manteríamos contato, e eu me comprometeria a levar e a divulgar seus escritos para o mundão. Jane queria que seus textos saíssem de lá, da iminência de sua destruição; que alcançassem outros espaços onde pudessem persistir e, sobretudo, serem lidos, ouvidos, reconhecidos. 
Na semana seguinte, cheguei no castigo e me dirigi à cela onde estava Jane. Diferentemente dos prévios encontros, desta vez ela não me esperava na boqueta. ${ }^{11}$ Uma senhora me recebeu enquanto Jane conversava descontraída no parapeito da janela/grade, tendo feito um breve aceno à minha chegada. Após algum tempo, Jane se aproximou da boqueta, perguntou como estava a rua, conversamos sobre as medidas tomadas pelo atual governo, contei das manifestações que estavam ocorrendo nas ruas ${ }^{12}$ e ela ponderou sobre a continuidade caótica que parecia alinhavar cadeia e rua. Nada falou sobre os papéis ou o projeto de reescrita dos livros. Nós nos despedimos. Na semana subsequente, a mesma sequência de eventos. Conversamos brevemente sobre questões do convívio entre o térreo do RO e as pessoas no castigo, e ela dizia estar aliviada, pois seus dias no pote chegavam ao fim. Na outra semana, já havia retornado ao pavilhão de origem.

A ideia de tentar reescrever parte do livro durante os dias de castigo e me entregar progressivamente mostrou-se dissonante do ritmo do pote e das demandas que a requisitavam. A urgência de denunciar o que aconteceu e fazer circular "um monstruoso filme de terror" deu lugar à preocupação com a rotina do castigo e com as relações que a envolviam. Nos últimos encontros não falamos mais sobre os livros e os planos futuros de publicá-los no mundão. Naquele momento, suas energias estavam centradas em cuidar do seu cotidiano, em elaborar formas de suportar o castigo junto com suas companheiras de cela. Conversamos sobre a rua, sobre o governo e trivialidades da vida e, em poucas semanas, "a ideia morreu" (Biondi 2014). ${ }^{13}$

\section{Ressaltos}

As marcas ressaltadas na barriga e nas costas de Jane em tons de roxo, verde e vermelho falam da agressão narrada por ela e confirmada pelas companheiras de cela. A atuação do Grupo de Intervenção Rápida, criado em princípios dos anos 2000 como "tropa de choque" dos agentes penitenciários, consiste em "intervenções preventivas em situações de risco, ou operações rotineiras de grande escala, como revistas em raios e unidades inteiras" (Godói 2015). Nessas operações rotineiras - referidas por Jane e outras/os presas/os como batidas - coletes, capacetes, escudos, coturnos, balas de borracha, cassetetes, bombas de gás lacrimogêneo e efeito moral, tubos de gás de pimenta e cães treinados adentram corredores e celas do pavilhão numa busca detalhista e feroz. Por meio da prerrogativa de "impor a lei e a ordem", invadem, reviram, destroem, desnudam, agridem. Coisas, ambientes e corpos das pessoas encarceradas sofrem, igualmente, a mesma irrupção violenta da vasculha. 
Não apenas a pessoa encarcerada, mas tudo o que dela transborda - sua família, afetos, seus pertences - é submetido ao exame minucioso e aviltante de todas as dimensões e em todas as suas cavidades. Após adentrarem os suntuosos portões da bucólica entrada da prisão, tanto as pessoas aprisionadas como os familiares que as visitam encontram na sala de revista o território liminar que marca a passagem do mundo livre para o mundo prisional. O processo de entrada desde as extensas filas até o espelho da sala de revista assinala "seu necessário e absoluto assujeitamento aos desígnios da administração penitenciária" (Godói 2015:189). Nesse sentido, o corpo da pessoa que visita, uma vez submetido ao escrutínio da revista rumo ao interior da prisão, adentra o continuum punitivo destinado aos corpos encarcerados. "Meio livre, meio prisioneira" (Godói 2015), a visita tem seus direitos e sua dignidade suspensos pela qualidade temporária e parcial de prisioneira que a torna, neste ato, objeto de suspeita e vasculha. Nessa qualidade, o corpo é compulsoriamente simetrizado às coisas que entram e àquelas que compõem o cotidiano da pessoa presa, igualmente sujeito a intervenções que violam, quebram, desnudam em ações de revista desde a sala de entrada até a intimidade dos barracos nos pavilhões.

Nas batidas da polícia, cassetetes, cães, escudos e coturnos inscrevem cores e deixam ressaltos nos corpos daquelas pessoas - entre elas, Jane - que chegam ao castigo com hematomas abaixo do pescoço após uma vasculha do GIR em seus barracos. Como uma das ferramentas centrais na mecânica prisional, estes agentes exercem sua tirania brutal sob o desígnio da "dominação serena do Bem sobre o Mal, da ordem sobre a desordem", cujas formulações morais servem de "adorno ao seu exercício" (Foucault 2011:73). Sendo a administração de violência física e verbal por parte desses agentes marca fundamental de sua atuação nos relatos e nos corpos daquelas/ es que encontravam-se no castigo, a sinistra previsão de Kafka em A colônia penal (1998) ganha contornos reais: a sentença não precisa ser anunciada. Ela será experienciada e marcada na carne da pessoa sentenciada - dela e de todas as suas extensões.

Os escritos gravados em papel que contavam a história de Jane dos anos vividos na prisão estavam imersos num sistema de forças e relações criado no envolvimento íntimo com o papel, a caneta e o corpo de Jane. Juntos, num movimento rítmico e dinâmico (Ingold 2015), produziram as narrativas que formavam o total de três livros completos. Estes, ora parte, ora extensão de Jane, foram igualmente assaltados e desassociados pela truculência da batida. Segundo Godói (2015), "a blitz é a maneira cotidiana de a administração penitenciária procurar desfazer certas associações entre homens e objetos, consideradas perigosas não só para a integridade de presos 
e funcionários, mas, sobretudo, para a austeridade da própria prisão". Desse modo, se como afirma Godói, a desassociação de pessoas e objetos advém da preocupação em relação a "associações perigosas", o apartamento de Jane de seus livros pelo policial encapuzado revela a ameaça percebida nessa conjunção.

Em Quadros de Guerra (2015), Butler reflete sobre a destruição dos poemas escritos por pessoas presas em Guantánamo, prática amplamente empregada pelo policiamento daquela instituição. Lidos pela autora como atos de resistência em relação à soberania global defendida pelos Estados Unidos, mesmo não sendo capazes de alterar o curso da guerra, os poemas dos prisioneiros apresentam consequências políticas quando emergem como "testemunhos de vidas obstinadas, vulneráveis", atos incendiários que vivem através da violência à qual se opõem (:97). O "grande risco" para a segurança nacional estaria, como alegava o Pentágono, no "conteúdo e formato" (:88) das cartas, uma vez que, ao chegarem ao conhecimento público, assinalariam a capacidade de essas pessoas sobreviverem e resistirem às condições precárias e desumanas a que eram submetidas. Ao extrapolarem os muros da instituição, as cartas colocavam em evidência práticas e políticas de Estado destinadas a fazer submergirem as pessoas nelas encarceradas. As palavras que delas escapam são consideradas "incendiárias" ao reivindicarem algo supostamente subversivo: o direito de ser reconhecido como vida; o direito de comunicar uma existência.

A discussão sobre a ocupação dos espaços públicos como um direito fundamental de aparecer, de se fazer reconhecido, é amplamente discutido em outro livro da autora, intitulado Corpos em aliança e a política das ruas: notas para uma teoria performativa de assembleia. Nele, Butler (2018) reflete sobre a distribuição diferencial da possibilidade de determinados grupos sociais comporem o espaço do aparecimento. Tornar-se "legível" na esfera social implica a formação de alianças e redes de ajuda nas quais as pessoas encontram pontos em comum, a partir deles podendo engajar-se coletivamente e construir condições de resistir à precariedade. Nesta obra, a autora expande o conceito de precariedade para pensá-lo segundo duas chaves: ao mesmo tempo em que é uma condição inerente a todos os viventes, já que todos dependem de fatores externos, sobretudo sociais, para a manutenção do corpo vivo, é também diferencialmente distribuída pela população, por razões políticas e econômicas.

Um exemplo importante da distribuição desigual das condições de precariedade se aplica às populações criminalizadas. Etiquetados como potenciais "criminosos", são especialmente os/as jovens negros/as moradores/ as de regiões periféricas que sofrem a exposição maximizada à violência 
arbitrária do Estado, quando não o assassinato deliberado sob o pretexto de uma "guerra às drogas", slogan que mascara o genocídio silencioso dessa população. Sua criminalização, além de destituir o indivíduo de direitos fundamentais como a proteção contra a violência e a morte, busca minar a legitimidade das formas de organização política pela garantia de direitos. Tal política de Estado, ao produzir mecanismos que não apenas etiquetam, mas efetivamente encarceram parcelas expressivas de uma população marcada por território, classe e cor, consegue, a um só tempo, confinar esses grupos e torná-los política e socialmente ilegíveis. Nesse prisma, impedir que certos escritos escapem dos muros das instituições carcerárias não busca apenas salvaguardar a instituição da denúncia de abusos e violências praticadas contra os encarcerados, mas pretende sobretudo minar as condições de aparecimento dessas pessoas enquanto vidas que têm o direito de existir e, portanto, que têm o direito de reivindicar os seus direitos mais fundamentais.

Os testemunhos de Jane sobre as diversas formas de violência sofridas durante os anos em que esteve encarcerada foram redigidas diante da "necessidade absurda de impor desesperada e obrigatoriamente as revelações de onde não existe um apocalipse próximo, e sim um apocalipse tão atual e presente como nossa própria existência". Segundo Jane, é por isso que "existir é uma prova de onde se deve agir, nunca omitir". Revelar esse apocalipse busca não só denunciar as experiências de humilhação e abuso vividas, mas também legitimar a sua própria existência em um quadro de inteligibilidade política e social. É preciso "existir" para que se possa agir politicamente. Butler (2018), de modo semelhante, assevera que o ato de testemunhar as violências sofridas pelo Estado requer, primeiramente, que aquele que fala possa ser reconhecido enquanto sujeito. Sem isso, não há uma base mínima a partir da qual se possa reivindicar o direito de uma existência digna de cuidado e proteção contra a precariedade. Portanto, quando essa existência não entra nos "quadros de inteligibilidade" das políticas de Estado, quando é reduzida à vida nua (Agamben 2008), torna-se alvo de violências incalculáveis e até mesmo do extermínio.

Em Os Afogados e os Sobreviventes, Primo Levi (2015), um sobrevivente do holocausto nazista, reflete sobre a importância de produzir testemunhos sobre a experiência nos campos de concentração, destacando o imperativo ético e moral de narrar as ações da barbárie nazista de modo a manter ativo o discernimento moral de todos. Em sua brilhante análise, o autor assinala um paradoxo vivido por aqueles que, como ele, conseguiram testemunhar o holocausto: aquilo que pôde ser narrado pelos que conseguiram sobreviver nunca vai ser capaz de refletir a essência da violência vivida nos campos nazistas, pelo simples fato de que quem viveu "o fundo" não sobreviveu para contar, ou tornou-se, em vida, incapaz de narrar. 
No entanto, o autor chama a atenção para as páginas de um diário que foram encontradas escondidas próximo dos crematórios de Auschwitz, redigido por algum dos participante dos chamados "comandos especiais" (Sonderkommandos). Igualmente prisioneiros do campo, os Sonderkommandos eram responsáveis pela gestão das câmaras de gás e dos crematórios, sendo eles mesmos exterminados, de tempos em tempos, e substituídos por outros, de modo a eliminar qualquer vestígio de suas atuações. A escrita desse diário, em condições tão extremas como as vividas nos campos de concentração, aparece como recurso último de resistência não só por testemunhar o que foi visto e vivido, mas sobretudo por marcar o registro da sua existência. Tais escritos não podiam ser atribuídos a um "cadáver ambulante, um feixe de funções físicas já em agonia" (Agamben 2008:49), como posteriormente foram assim referidos os prisioneiros que compuseram as práticas de extermínios a mando das SS. As páginas do diário afrontam o projeto nazista justamente quando deixam a marca da sua humanidade, a despeito de todas as estratégias para desnudá-la por completo.

Ainda que o ato de narrar as formas de violência sofridas por políticas de Estado seja para Primo Levi (2015) um imperativo ético, ele assinala situações em que falar sobre o trauma vivido torna-se uma impossibilidade, pois o que precisaria ser dito pertence ao domínio do indizível. Na etnografia feita por Veena Das (2007) com mulheres que vivenciaram tremenda violência em função dos processos de repartição da Índia, a autora aprofunda a reflexão sobre as formas de narrar e comunicar a dor. A vivência com essas mulheres mostrou, com o tempo, que a inviabilidade de falar sobre o trauma dava lugar a formas silenciosas de comunicar o sofrimento. Ao trazer a análise para o plano do ordinário, do cotidiano, ações singelas como o preparo do alimento, os afazeres diários, a organização dos ambientes e o cuidado com o cultivo das relações apareciam como modos de mostrar os efeitos da violência pelo exercício persistente de "descer ao cotidiano" e produzir uma vida possível. De acordo com Das, essas são formas de agência que não aparecem como atos heroicos e fantásticos de resistência, mas que são exercidas nas sutilezas diárias de tornar o mundo que fora devastado um lugar habitável.

Ao ter seus escritos e pertences destruídos pelos policiais do GIR, Jane sabia que enfrentaria um longo e vagaroso período de reconstrução dos seus livros e das condições do seu barraco. O primeiro ímpeto de reescrever o quanto antes as denúncias dos abusos e das violências sofridas deu espaço, ao longo dos dias no pote, a outras formas de reparação do que foi perdido. As marcas no seu corpo ressoavam os relatos feitos por ela e suas colegas sobre as agressões deflagradas nas batidas policiais. 
Tão importante quanto escrever um testemunho como forma de resistência às tentativas de anulação da sua existência era retomar o cotidiano e se associar àquelas que, com ela, compartilhavam as mesmas condições de precariedade. Naquele registro, manter-se viva e reivindicar um lugar de reconhecimento enquanto pessoa se constituiu como forma de resistência aos esforços institucionais de anulação da sua subjetividade. Ela própria sabia das possibilidades exíguas de encontrar condições através das quais seus escritos poderiam não apenas sair da prisão, mas achar plataformas onde poderiam ser lidos e reconhecidos.

Como nos lembra Butler em Corpos em Aliança (2018), para se agir politicamente são necessárias alianças e relações a partir das quais se formam redes de suporte para a promoção da legibilidade política e social. Toda ação social precisa de um outro para acontecer. Nesse sentido, são necessários suportes para poder falar e para ter sua fala reconhecida. Sobre esta questão, a antropóloga indiana Gayatri Spivak (2010a) nos coloca um importante questionamento: pode o subalterno ${ }^{14}$ efetivamente falar? A pergunta posta pela autora ressoa as dúvidas que espreitavam meus encontros com Jane: ainda que seus escritos não tivessem sido destruídos, teriam eles encontrado condições e plataformas para serem lidos e reconhecidos?

Em contundentes críticas ao pensamento que toma o Ocidente como Sujeito de fala, Spivak indaga sobre as condições de possibilidade que permitem ao subalterno - em especial o sujeito subalterno feminino - falar. De forma a refletir sobre as maneiras e os limites da escrita subalterna, a autora parte do caso específico de uma mulher indiana - que em outra ocasião (Spivak 2010b) revela ser a irmã de sua avó - chamada Bhuvaneswari Bhaduri que, aos 17 anos, comete suicídio. De acordo com a autora, nas escrituras hindus, o suicídio é amplamente repreendido, todavia, em alguns poucos casos é sancionado, como acontece na imolação de viúvas sobre a pira funerária do marido morto, prática conhecida como sati. Nesse cenário, Spivak mostra que o suicídio de Bhuvaneswari aparece justamente ao revés das motivações que animam o sati.

O suicídio tornou-se um enigma, já que, como Bhuvaneswari estava menstruada na época, claramente não se tratava de um caso de gravidez ilícita. Quase uma década depois, foi descoberto que ela era membro de um dos muitos grupos envolvidos na luta armada pela independência da Índia. Ela tinha finalmente sido incumbida de realizar um assassinato político. Incapaz de realizar tal tarefa e, não obstante, consciente da necessidade prática de confiança, ela se matou. Bhuvaneswari sabia que sua morte seria diagnosticada como resultado de uma paixão ilegítima. Ela, então, esperou o início da menstruação (Spivak 2010:123). 
O dúbio privilégio da reivindicação do suicídio sati prescreve que a viúva deve aguardar publicamente o fim da menstruação para enfim imolar-se. Dessa forma, Spivak vê no suicídio de Bhuvaneswari a reescrita de um texto social, uma vez que ela se deu "ao imenso trabalho de deslocar (não simplesmente negar) na inscrição fisiológica de seu próprio corpo seu aprisionamento em uma paixão ilegítima por um único homem" (Spivak 2010). A problemática central que Spivak busca salientar é que, apesar do esforço de Bhuvaneswari em promover uma escrita subalterna do texto social do suicídio sati através da sua morte, tal ato se tornou publicamente obscuro e, suas motivações, desconhecidas.

O que a autora pretende concluir a partir do caso de Bhuvaneswari é que, quando não existe nenhuma base (background) institucional válida para resistência, não são produzidas condições para que a voz do subalterno seja reconhecida. O caso do suicídio sati como prática prevista e sancionada pelas escrituras hindus era sustentado por uma validação institucional e, nesse sentido, a expressão dessas mulheres estava amparada institucionalmente, promovendo condições para ser lida, ouvida. Contudo, "a resistência de Bhuvaneswari contra os axiomas que animavam sati não podiam ser reconhecidos. Ela não podia falar" (Spivak 2010:228).

Spivak (2010b), assim, argumenta que as condições do suicídio e da (não) repercussão da escrita subalterna de Bhuvaneswari faziam com que a autora fosse necessária para lê-la, ouvi-la, fazê-la falar por extensão, "by default", 15 isto é, que trouxesse à tona sua escrita ao público diante da ausência de condições de fala. Spivak, em seguida, reflete sobre a importância do/a professor/a na formulação de projetos de escuta "dos subalternos" de maneira a constituir espaços de representação na esfera pública para que possam, assim, representar a si mesmos. Segundo ela, referindo-se às grandes universidades mundialmente conhecidas: "essas escolas são coisas frágeis, enterradas num sistema de educação que assegura que o subalterno não vai ser ouvido, exceto como mendigo" (:229, tradução minha).

É justamente como mendigo a pedir esmola que Jane suplicava pela atenção de um bocadinho da escuta do/a leitor/a para "segredar profecias revestidas na frieza de uma sociedade fantasiada de egressa". A súplica de Jane por um bocadinho de atenção parece partir da prerrogativa de que não existe respaldo ou ouvintes interessados na escuta das palavras que deseja revelar. Como no caso dos poemas dos prisioneiros de Guantánamo tornados públicos, tais escritas tiveram de ser formalmente submetidas à permeabilidade altamente restritiva da fiscalização institucional. ${ }^{16}$ Se os escritos de Jane não tivessem sido destruídos pelo policial encapuzado, 
ao menos que saíssem do presídio por algum meio não institucional (como foi o caso dos únicos parágrafos que conseguiu me segredar), certamente teriam de passar pela inspeção sancionadora da máquina carcerária. Como mostra Taets (2012), a fiscalização das cartas que entram e saem das penitenciárias femininas do estado de São Paulo por agentes carcerárias consiste na leitura, vasculha e fundamentalmente na censura dos conteúdos considerados "inadequados" - nesse registro, pode-se antever que conteúdos entendidos como "perigosos" são, por extensão, altamente "inadequados". Colocar o/a leitor/a "cara a cara com um monstruoso filme de terror", por meio de "revelações de onde não existe um apocalipse próximo, e sim um apocalipse atual", são colocações que almejam fazer ver justamente aquilo que os mecanismos institucionais querem submerso.

Ao me entregar o preâmbulo do livro que intitulou Arquivo Morto, Jane parecia fazer de mim um (dentre outros possíveis) vaso comunicante (Godói 2010) que poderia levar esses escritos para fora da prisão, sem incorrer no risco de tê-los fiscalizados e possivelmente censurados pelas/os agentes carcerárias/os incumbidas/os. No entanto, uma vez fora da prisão e finalmente expressos em texto passível de circulação, suas palavras são submetidas às circunstâncias que impossibilitam a divulgação da sua identidade e consequente exposição da autoria. ${ }^{17} \mathrm{Se}$, por um lado, imprimir esses parágrafos num artigo parecia uma alternativa viável para levar seus escritos para fora da prisão e, como indica Butler (2015), produzir empatia e reconhecimento dentro de "quadros de inteligibilidade" daquelas/es que o leem, por outro lado, recaía no perigoso risco de "fetichizar o Outro", como previne McClintock (2010).

Desse embate, segui as proposições de Spivak e busquei olhar para a escrita de Jane da mesma forma que via os hematomas ressaltados na sua pele: como textos de uma escrita subalterna. Textos que emergem das inúmeras violações a que são submetidos, mas que persistem através e contra elas, ainda que sem o respaldo de espaços institucionalmente reconhecidos de fala e escuta. Assim, diante dos constrangimentos inerentes ao ambiente prisional e das contingências da realização da pesquisa, a fala de Jane chega a este texto por extensão e por meio da irremediável constatação de que "a mulher subalterna não pode falar", a não ser em aliança. Ainda que apenas uma página, é pelo comprometimento com a necessidade de se fazerem alianças que este artigo busca trazer essa carta à luz e, com isso, assinalar uma existência, uma determinada existência. 


\section{Anestesias}

No dia 13 de maio de 2016, entre as anotações do caderno de campo sobre a visita ao castigo, estão as seguintes cenas:

Cheguei no castigo e encostei na boqueta da primeira cela ao lado esquerdo, onde estava Marina. Assim como na última semana, ela continuava bastante chorosa, melancólica. Segundo ela, "sua mulher" foi transferida para Tremembé sem aviso prévio. A chegada dos guardas no barraco trouxe o anúncio súbito do bonde de sua companheira. Desesperadas, tentaram agredir os guardas, resistir à tentativa de levá-la. As duas foram escoltadas ao castigo - uma no pavilhão do RO, a outra no castigo de Tremembé. Marina, sozinha na cela do pote, dizia estar muito depressiva. No entanto, relatava que uma enfermeira muito boazinha estava ajudando-a: assim que terminava o plantão saía e levava para ela remedinhos para dormir. Marina dizia ser esta a única forma de suportar os dias de castigo sem surtar, sem se machucar, sem fazer alguma coisa que poderia piorar sua situação.

Na próxima cela, uma garota reclamou que estava com muitos furúnculos, cerca de 120. Com o corpo cheio de pontos vermelhos inchados, dizia ter muita dor, precisava de algum tratamento porque os furos não paravam de inchar e aumentar. No entanto, dizia que a única coisa que as senhoras davam para ela era dipirona.

Nas duas últimas celas não consegui falar com ninguém, todas pareciam estar dormindo profundamente. Como não havia ninguém no trânsito, desci ao RO.

Os excertos do caderno de campo acima expostos apresentam cenas comuns e, por isso, representativas das visitas ao castigo. Trânsitos abruptos, separações forçadas, problemas de saúde mas, particularmente, a presença de psicofármacos no cotidiano da prisão como fatores ordinários. Diferentemente da visão que trazia comigo sobre a prisão como ambiente de absoluta escassez material, a presença massiva de medicamentos psiquiátricos que irrompiam por celas e corredores revelava outro aspecto dessa realidade.

Entre as celas do RO, a presença de expressões vagarosas e pesadas, a escuta aérea e olhares contemplativos do vazio - efeitos desencadeados pelo consumo de psicofármacos - compartilhavam aspectos sensoriais de muitas pessoas que circulavam por seus corredores. No entanto, demorei algum tempo para perceber as diferentes modulações sensoriais que eram produzidas na (e pela) vivência do pote. Dispostas/os por cubículos cinzas abafados, insalubres, esvaziados de utensílios e abarrotados de pessoas, 
por períodos de 10 a 30 dias de movimentação restrita e alimentação precária, o sono induzido e prolongado era, para muitas/os, ferramenta e possibilidade de agenciar as horas que demoravam a passar.

Os remedinhos para dormir dos quais falava Marina eram os mesmos que muito provavelmente faziam adormecer as cerca de cinco pessoas nas duas últimas celas do castigo. Estas, por volta das 15h, pareciam arrebatadas por um estranho sono compartilhado. Era absolutamente comum passar pela boqueta do pote e encontrar uma, duas ou mesmo todas da cela dormindo profundamente. Se tinha algum recado importante, tentava acordá-las, caso contrário, seguia em frente. A indução do sono era, nesse contexto, uma maneira de lidar com a ansiedade, com o sofrimento e a revolta; uma forma de autocontrole para "não surtar, não se machucar" nem prejudicar sua - já fragilizada - situação. "Surtar", nesse contexto, poderia desencadear sua transferência ao castigo em outra improvável unidade prisional, onde as condições de sobrevivência poderiam ser ainda piores.

Adam Reed (2007), em seu estudo sobre a ação dos cigarros numa prisão na Papua Nova Guiné, propõe pensar através dos cigarros para compreender a realidade prisional, tendo em vista que tais objetos são altamente valiosos na economia informal de prisões por todo o mundo. O autor aponta para o encarceramento como tecnologia que produz sentimentos de preocupação, sofrimento e um estado de ansiedade contínua; diante dessa experiência, o cigarro aparece como ocupação e alívio temporário dessas sensações. Segundo o autor, "o verdadeiro significado dessa atividade se sustenta nos efeitos que produz na mente do fumante. Durante todo período que compartilha o fumo, este é animado pela promessa de escapar às dores do confinamento" [...]. O ato de fumar, assim, é capaz de impactar os sentidos do interno e "temporariamente anestesiar ou 'matar' o que chamam de seu 'sentido de memória'", que, nas falas de seus interlocutores, aparece como causa primordial da ansiedade (:35, tradução minha).

É evidente a importância dos cigarros no cotidiano da prisão, tanto por se ter configurado como moeda de troca em muitos contextos prisionais quanto pelos efeitos químicos que produzem sensações de relaxamento e uma certa anestesia diante das ansiedades provocadas pelo confinamento. $\mathrm{Na}$ PFS, a circulação e o consumo de cigarros manifestavam-se nos gritos vindos do castigo que pediam às senhoras os maços que ficaram no pavilhão de origem, e também pela passagem de cigarros nos barbantes jogados de uma cela a outra e pela incessante nuvem branca e odor acentuado que passeavam pelo denso corredor. Ainda assim, a presença de outras substâncias com maior potencial de anestesia parecia quase concorrer com o cigarro em termos de frequência e intensidade. Um sapatão preso no castigo certa vez me disse 
que "não dá pra tirar muitos anos de cadeia careta, não tem psicológico que aguenta". Referia-se ao uso continuado que fizera de maconha e cocaína nos últimos sete anos em que esteve preso. Sua fala parecia comunicar que, independente da substância escolhida, inevitavelmente se fará uso de algo que consiga, em alguma medida, amortecer os efeitos do cárcere.

Como tática para suportar o tempo no castigo, Marina, dentre outras pessoas que observei dormir longa e excessivamente nos dias de pote, parecia fazer uso de medicamentos na busca para enfraquecer suas faculdades sensoriais durante esse período. A ansiedade quanto às consequências do castigo na progressão da pena, ${ }^{18}$ a insegurança em relação aos pertences deixados no barraco, o afastamento dos afetos que ficaram no pavilhão, a (quase) impossibilidade de contato com familiares, a (ainda maior) redução material e espacial, a convivência peremptória e acumulada de pessoas na mesma cela de dez a trinta dias são fatores múltiplos e condensados que fazem parte da prerrogativa do castigo: punir, produzir sofrimento. Em resposta a isso, amorteciam taticamente seus sentidos, dilatando a experiência-no-mundo (Csordas 2009) a uma frequência miúda que anestesia, adormece, abafa, silencia.

Diazepam, Lorazepam, Clonazepam, Fluoxetina e Paroxetina ${ }^{19}$ estavam entre as substâncias mais comuns nos medicamentos que pude observar no RO. De forma geral, apresentam efeitos sedativos, causam sonolência, diminuição da atenção, da concentração e dos reflexos, bem como produzem dependência e reações de abstinência (Cordioli 2017). O enorme afluxo dessas substâncias parecia conviver com a reiterada e normalmente única medicação para outras indisposições (desde furúnculos a infecções, inflamações, problemas gástricos, respiratórios, cardíacos, intestinais): dipirona. Na falta de remédios adequados, recorrem a soluções caseiras improvisadas para sanar ou ao menos amenizar sintomas de dor ou mal-estar.

Em certa ocasião, uma mulher isolada nas celas do castigo me disse que, para eliminar os fungos que proliferavam pelos seus pés, aplicava-lhes diariamente uma mistura de água sanitária e álcool, enquanto aguardava o atendimento médico que há meses não chegava. Em casos mais severos, sintomas são acumulados até desembocar em situações-limite que forçam a mecânica administrativa a conduzir o/a doente ao Centro Hospitalar do Sistema Penitenciário (CHSP) para atendimento de emergência. Quando nenhum atendimento ou bonde para o CHSP chega a tempo, mais um corpo morto é transferido para o necrotério. ${ }^{20}$

O definhamento da população carcerária como resultado de uma política de desassistência médica geral convive, de modo sintomático, com a proliferação de psicofármacos que escoam por prescrições médicas e pululam 
pelos corredores e celas das prisões. Tanto no Brasil como no mundo afora, pesquisadores apontam para o crescimento alarmante de diagnósticos de transtornos mentais e consumo de psicotrópicos no ambiente carcerário (Wacquant 2007; Berárd \& Chantraine 2008; Malventi 2009; Fassin 2015; Matsuda 2016; Mallart 2019; Roseira 2017, entre outros). A análise desse fenômeno passa, evidentemente, pela consideração acerca do crescente processo de psiquiatrização da vida no tecido social como um todo. Em uma retomada histórica do desenvolvimento da psiquiatria, Russo $(2006,2017)$ mostra como, na passagem do século XX ao XXI, o Ocidente foi marcado pela multiplicação exponencial de categorias de distúrbios mentais por meio da paulatina adoção de uma visão predominantemente biológica das doenças psiquiátricas, consolidando a hegemonia da chamada "psiquiatria biológica e farmaceuticamente orientada" na terapêutica dos distúrbios mentais. Neste cenário, os espaços prisionais, laboratórios por excelência da psiquiatria e das ciências criminais (Foucault 2002, 2007), permanecem sendo plataformas privilegiadas para a expansão e a potencialização de diagnósticos psiquiátricos e de comportamentos tidos como patológicos.

Um artigo apresentado pelo International Journal of Law and Psychiatry, publicado em 2000, estima que instituições correcionais nos Estados Unidos guardam duas vezes mais pessoas com transtornos mentais graves do que hospitais psiquiátricos. Segundo a mesma pesquisa, o sistema prisional dos países europeus indica uma taxa de $63 \%$ do conjunto de prisioneiros com sintomas que se enquadram nos critérios de desordem mental. A referência a este artigo foi encontrada no texto de Didier Fassin L'asile et la Prison (2015), no qual o autor se debruça sobre o atual fenômeno de crescimento de quadros diagnosticados como transtornos mentais entre a população carcerária. Fassin pondera que, ainda que alguns quadros de transtorno precedam o próprio aprisionamento, é razoável pensar que as condições de confinamento são responsáveis por agravá-los. De todo modo, seja pela produção, seja pela complicação de quadros de transtorno mental, o autor destaca a vulnerabilidade psicológica e o sofrimento em suas diversas formas como elementos constitutivos da vida na prisão (:88-89).

No contexto brasileiro, Mallart (2019) tece ponderações acerca do uso de psicofármacos em unidades prisionais e sugere que um processo de "psiquiatrização das prisões" se desdobra através do aperfeiçoamento das tecnologias de controle e gestão das populações tidas como indesejáveis. Nesse cenário, lógicas manicomiais são atualizadas dentro do cárcere de modo a criar soluções administrativas de gestão da superlotação, ao mesmo tempo em que regulam neuroquimicamente condutas individuais de sujeitos considerados desviantes e perigosos. Segundo o autor, 
muito além dos objetivos de tratamento e de cura, tais substâncias espraiamse no interior das muralhas como um expediente necessário à gestão de espaços e populações, cuja funcionalidade consiste em amenizar efeitos desencadeados pela mecânica prisional. [...] Na medida em que já não se trata de curar ou tratar, mas apenas de administrar espaços, corpos e sintomas, fazendo com que os indivíduos sejam apenas aquilo que já são, a potência dos psicofármacos em unidades prisionais precárias e superlotadas reside na gestão neuroquímica (:192).

Essa gestão neuroquímica dos corpos por parte da administração prisional, responsável por dopar, dobrar e conter, convive também com o consumo de substâncias psicotrópicas pelas/os internas/os, cujos efeitos são agenciados por elas/es para finalidades próprias. Os remedinhos para dormir dos quais Marina dizia precisar para suportar o castigo e permanecer calma, assim como aqueles que pareciam administrar um sono profundo e duradouro entre as mulheres que passavam temporadas no pote, não podem ser lidos apenas na chave da funcionalidade em relação aos propósitos de gestão e controle prisional. Ainda que conveniente à administração, o uso intencional e deliberado de psicofármacos a fim de gerir o humor e o sono configura-se também como tática para suportar o insuportável, amortecendo efeitos perniciosos do cárcere.

O uso dos psicofármacos, nesse registro, ressoa os usos feitos de outras substâncias que alteram a percepção, tal como o cigarro, a maconha, a cocaína ou o álcool. Motivado pela expectativa de escapar às dores do confinamento, o consumo dessas substâncias se aparelha em meio à produção temporária de sensações que desviam a atenção do momento presente e anestesiam as frustrações de um porvir distante e incerto. $\mathrm{Na}$ situação do castigo, uma "prisão dentro da prisão", frase repetida inúmeras vezes por aqueles que transitam pelo cárcere, a necessidade de superar a ansiedade dos dias que se alongam é ainda mais premente. Ao mobilizar uma certa circulação interna de psicofármacos ${ }^{21}$ o tempo do castigo passa a ser regulado pela administração das sensações corporais: tirar o castigo dormindo ou simplesmente ingerir substâncias que diminuam a ansiedade podem ser lidas como formas de resistir à cadeia.

Gerir o sofrimento, dentro ou fora da prisão, tem levado milhares de pessoas a procurar tratamento psiquiátrico para conseguirem suportar as mazelas da vida e, com isso, não sucumbirem. Sem eximir os efeitos nefastos de uma gestão penitenciária que lança mão da disseminação de psicofármacos como forma de conter motins e manejar a superlotação, não se pode também, por outro lado, resumir o consumo dessas substâncias a uma 
dominação pelos ditames administrativos. A questão que precisa ser colocada é: quais condições de vida levam as pessoas a recorrerem à permanente anestesia dos sentidos para conseguirem suportar o cotidiano? Ou ainda: tornar o insuportável suportável é uma forma de resistir à destruição das formas de vida?

\section{Fissuras}

No pavilhão do RO, o corpo como território de exploração para a produção de formas de vida mais salutares não se manifestava apenas pela administração de psicofármacos, mas pela incisão de traços ao longo do corpo. Pelos dois andares do pavilhão, as escarificações na pele pareciam quase tão comuns quanto tatuagens. Em sua maioria desenhavam braços, mas também apareciam nas coxas e no colo do peito. Os cortes encontravam vazão em pedaços de vidro, lâminas ou qualquer objeto cortante à mão - cortes superficiais, outros profundos, alguns repletos de costuras e fios dos inúmeros nós de pontos feitos no hospital. Por vezes, confundiam-se e misturavam-se com traços foscos da tinta improvisada nas tatuagens.

Simone, moça jovem de cabelos longos e trançados, disse ter sido transferida para o pavilhão do RO para "tratamento psiquiátrico". Durante duas semanas, Simone acompanhou Vera e eu na sala/cela de leitura pelas horas em que permanecemos no pavilhão. Sua fala enrolada, olhos semicerrados e dispersos mostravam alguns dos efeitos do uso intensivo de psicofármacos. Em um dos nossos encontros, Simone queixou-se do seu marido, relatando os episódios reiterados em que foi agredida por ele. A preocupação com o paradeiro do marido e seu bem-estar convivia com o medo de encontrá-lo novamente e reviver as costumeiras agressões. Ainda assim, pediu que eu fizesse contato com ele e trouxesse a resposta na semana seguinte. Uma semana depois, fui encontrar Simone em sua cela para lhe passar o recado, mas ela já não estava mais lá. Informaram-me que, naquela semana, tivera um "surto" e fora mandada para o "manicômio de Franco da Rocha". ${ }^{22}$ Todavia, na semana seguinte Simone já estava de volta ao RO.

Quando nos abraçamos, eu me assustei ao sentir algo pinicando minha costela. Ao me afastar, percebi que era seu braço: uma camada espessa de linhas e nós cobria toda a extensão do seu antebraço. Cortes profundos e sequenciais desfiguravam seu formato. Ela, então, olhou para a camada de pontos e disse: "Olha o que aconteceu comigo, tentei me matar". Apesar da feição abatida e da fala dificultosa, Simone dizia estar bem e positivava sua rápida estadia em Franco da Rocha: “Estou bem melhor, mais calma, 
passei só um dia no manicômio. O bom foi que diminuíram os remédios, antes eram treze, agora só oito. A médica me examinou e percebeu que eu já tava melhor, não precisava ficar lá, dai me mandou de volta". Aliviada, passava a mão pelo braço escarificado e dizia ter melhorado, uma vez que os cortes estavam mais sequinhos.

A diminuição dos remédios de Simone "de treze para agora só oito" pela médica do HCTP de Franco da Rocha indicava uma avaliação de "transtornos mentais" que prescrevia - se não antes de sua detenção, como consequência dela - determinada dose diária de medicamentos controlados. No seu caso, os efeitos acachapantes dessas pílulas não foram suficientes para conter "o surto" que desencadeou seu autoflagelo e tentativa de suicídio. Se o efeito esperado desses medicamentos está na sedação e na anestesia dos sentidos, a irrupção violenta contra si parece transplantar a fronteira nebulosa que supostamente impermeabiliza sua relação com o mundo. Em outras palavras, se, por um lado, existe um esforço institucional em possibilitar uma enorme vazão de prescrições e pílulas psiquiátricas a fim de conter e comprimir insurgências várias, por outro lado, a irrupção de comportamentos que "saem da linha" não param de diagnosticar a impossibilidade de abafar a pressão de um contexto prestes a explodir.

Dinho, sapatão que acabara de ser transferido para o RO, observou quando Simone falou sobre o braço escarificado e sua rápida passagem pelo HCTP de Franco da Rocha. Sentado num banco ao nosso lado, apontou para o braço de Simone e disse que "aquilo não era nada" perto dos cortes que ele mesmo já fez no seu próprio corpo. Com espírito quase competitivo, começou a mostrar, com entusiasmo, a série de cortes extensos que infligiu em si mesmo, quase sempre com navalha; algumas marcas na barriga, outras no colo do peito. Mostrou a cicatriz profunda no tórax e disse ter "cortado e enfiado o dedo bem fundo, para sangrar bastante", uma vez que gostava de ver "aquele sangue bem escuro descer"; com isso, sentia-se melhor. Parecia satisfeito em provar que a extensão e a profundidade dos cortes pelo seu corpo superavam aqueles visíveis no braço de Simone.

Em outra ocasião, ao passar pelas celas do castigo, reencontrei Caio, cuja passagem pelo pote começava a se tornar frequente. Com semblante sorridente, contava sobre suas trajetórias de idas e vindas à prisão. Dizia que a última cadeia foi bem longa e naquele período casou com uma mulher, com quem passou a dividir o barraco. Depois de anos juntos, o alvará de soltura de Caio chegou, enquanto para sua companheira ainda faltavam alguns anos. Decidiram permanecer juntos, na medida em que ele se comprometia a visitá-la aos domingos, fazendo contato sempre que possível. Dois meses depois, Caio ficou sabendo que "sua mulher" o estava traindo: 
"Ah, eu tinha que resolver isso de perto, precisava estar aqui pra ver se era isso mesmo e, se fosse, ela ia pagar. Então fui pra rua, roubei o primeiro playboy que encontrei e esperei a polícia chegar pra me levar". Dizia ser excessivamente ciumento e, quando ficava muito nervoso, fazia cortes no seu braço. De forma semelhante a Dinho, falava que ver e sentir o sangue escorrer causava uma sensação de alívio.

Quando fico muito bravo, muito estressado ou ansioso... É um jeito de ficar mais calmo, sabe? Se fico muito pilhado, preciso de alguma coisa pra aliviar, pra acalmar. Mas não é sempre... é quando tá difícil mesmo. Na hora em que o sangue desce dá aquele alívio, que nem uma droga. [...] Não é pra me matar não. Porque se eu quisesse me matar, já tava morto.

Os braços de Caio mesclavam contornos das tatuagens com as várias linhas brancas e avermelhadas de cortes antigos e recentes, que se confundiam pela superficialidade dos traços. Diferentemente das marcas profundas no braço de Simone, ou das reentrâncias no colo do peito e barriga de Dinho, as escaras de Caio eram esparsas e menos visíveis. Com intensidades e profundidades variadas, os diversos cortes pelo corpo apareciam nas falas de Caio e Dinho como tática de gerir o sofrimento, a ansiedade, a cólera. As fissuras feitas na pele pareciam externar dores subterrâneas que, transpostas à superfície, eram materializadas em fluido viscoso - ganhavam densidade, cor e temperatura.

Para Dinho, o sangue escuro e espesso que chegava à epiderme pela maior profundidade do corte trazia com ele sensações de alívio e bemestar. O estresse, a ansiedade e o ciúme de Caio eram amenizados quando o escorrer brando do líquido viscoso irrompia da pele - "como uma droga" - parecendo amortecer os ânimos exaltados e tranquilizar a inquietude do cotidiano. Para Simone, por sua vez, os cortes representavam a tentativa malsucedida de dar fim à própria vida. Cortes sequenciais e profundos que deformaram seu braço eram explicados por ela como esforço para acabar com a dor. Neste caso, o fim da dor viria ao dar cabo à vida. Com isso, somaria mais um ao crescente número de suicídios que silenciosamente preocupam a administração prisional e os órgãos governamentais.

Em discussão sobre as diferentes formas de sofrimento advindas da experiência do aprisionamento, Fassin (2015) ressalta o aumento dos índices de suicídio no universo carcerário ${ }^{23}$ e sua relação com o agravamento de fragilidades psíquicas entre detentos/as. Mais que um problema concernente à psicologia das pessoas encarceradas, o autor afirma ser esta uma questão de políticas de Estado e das formas tortuosas por meio das quais se produzem dor e sofrimento na prisão. Ao relatar estratégias governamentais para 
contenção dos casos de suicídio, Fassin narra um caso bastante emblemático que pôde acompanhar na prisão onde realizava visitas. Entre os esforços da administração para conter suicídios estava a vigilância redobrada de pessoas com queixas ou expressões de ansiedade e angústia. De forma a impedir possíveis tentativas de suicídio, passaram a isolá-las e a realizar rondas de duas em duas horas. Caso a pessoa estivesse dormindo, acordavam-na de modo a certificar-se de que ela estava viva. O autor relata que o presidente da comissão encarregada da contenção de suicídios escreveu a seguinte anotação no seu caderno de acompanhamento: "Detento ansioso. Multiplicar as rondas aumenta sua ansiedade" (:94)

As estratégias governamentais descritas por Fassin na contenção dos suicídios assemelham-se àquelas que pude observar no RO. No caso de Simone, o "surto" marcado pela tentativa de suicídio teve como "solução" sua condução compulsória ao Hospital de Custódia de Franco da Rocha. Para seu alívio, a avaliação positiva da médica diminuiu a quantidade de pílulas e reconduziu-a ao pavilhão do RO. No período em que visitei o RO, pude notar a preocupação compartilhada por funcionárias/os e presas/os em relação ao aumento de suicídios na unidade. No prazo de um ano e meio, entre população de quase 3 mil pessoas presas, havia uma média de dois suicídios a cada três meses. Contudo, em determinada ocasião, houve rumores da ocorrência de três suicídios em menos de um mês. Nesse período notou-se uma inquietação generalizada: nas reuniões da Pastoral Carcerária, nas conversas com presas/os no RO, no castigo e nas medidas tomadas pela administração, a preocupação quanto ao aumento dos casos era patente. A postura da Direção foi isolar pessoas que ameaçavam suicídio nas primeiras celas do RO, onde ficariam próximas ao portão/grade do pavilhão e da observação constante das guardas. Assim, percebia-se o esforço efetivo em conter ameaças de suicídio.

Na perspectiva de Caio e Dinho, no entanto, os cortes no corpo não sinalizavam a busca pelo fim da vida. Pelo contrário, pareciam justamente encontrar meios de torná-la possível. Uma forma de cuidado de si. Assim como aquelas/es que lançavam mão do uso intensivo de medicamentos psiquiátricos ou de outras drogas, pareciam amortecer temporariamente os sentidos e amenizar a ansiedade, a cólera, o sofrimento. Ao expelir o sangue, deixa-se escoar para fora do corpo a substância de um sofrimento que já não cabe no seu interior. Nesse registro, fazer sangrar seria, no limite, uma forma de habitar um mundo (in)vivível. 
Suely Rolnik (2003), em um simpósio no Instituto de Psicologia da UFRGS, disse que "a potência de resistência é convocada quando a crueldade inerente à vida destrói formas de existência". Sua definição da "crueldade inerente à vida" aproxima-se muito daquilo que Butler (2018) chama de "precariedade": uma condição trágica inexorável que impulsiona todo movimento vital. Para existir enquanto humano são necessários esforços para alcançar um outro e, com ele, produzir formas de associação, de aliança e de luta. Dependemos invariavelmente uns dos outros porque existimos a partir da precariedade e, imersos nela, lutamos para superá-la. Essa batalha ou esse empenho coletivo de superar a precariedade é o que movimenta a vida. No entanto, a mesma condição universal que atravessa todos é também politicamente produzida, de modo a distribuir seletivamente intensidades e condições de associação para superá-la. Desse modo, se para Butler toda ação é política e possui necessariamente uma dimensão agregadora, a escolha de defender certas formas de vida em detrimento de outras configura-se como genocídio de uma população: ou são produzidas formas de conviver em aliança, ou certos grupos são exterminados para que outros prevaleçam.

A crueldade de que fala Rolnik, uma violência "positiva ou ativa" que se impõe como necessidade vital, é também a crueldade que destrói formas de existência, contra a qual são necessárias formas criativas de resistência para que a vida possa continuar fluindo. As potências de criação e de resistência são, assim, convocadas em situações liminares quando o mundo conhecido se desfaz e se torna imperativo germinar outras formas de habitá-lo, para que a vida possa perseverar.

As linhas que se movimentam nos desenhos e nas cartas produzidos por Jane extrapolam os papéis e deixam registros nos corpos daquelas/es que a procuram para gravar na pele suas próprias narrativas. Os "escritos incendiários" destruídos pelo policial encapuzado sofrem a mesma violência que tenta dobrar o corpo de Jane, arrastando-o pelo corredor e espancando-o até o castigo. Na tentativa de desfazer "associações perigosas" entre pessoas e coisas, tais práticas de Estado negligenciam a potência criativa que germina a cada explosão de crueldade. Ignora que os hematomas deixados na pele viram textos que impõem "desesperada e obrigatoriamente revelações de [...] um apocalipse tão atual e presente como nossa própria existência". Esquece ou se recusa a ver que o corpo dopado ou anestesiado suporta em vida as dores produzidas para fazer morrer. Esquece que o sangue que escorre pode ser capaz de fazer a vida perseverar, em vez de extingui-la. Nesse prisma, permanecer vivo em face de uma política que nem sequer admite sua existência como digna de cuidado e proteção é, por si só, uma forma de resistência. 
Recebido em: 15 de março de 2019.

Aprovado em: 18 de março de 2020.

\author{
Sara Vieira Antunes \\ É mestra (2017) em Antropologia Social pela Universidade Estadual de Campinas \\ (UNICAMP) e doutoranda no Programa de Pós-Graduação em Antropologia \\ Social pela Universidade de São Paulo, USP (bolsista Fapesp). Integra o Núcleo \\ de Antropologia do Direito (Nadir-USP) e desenvolve, atualmente, a pesquisa \\ "Perigosos e Inimputáveis: um estudo da medida de segurança em múltiplas \\ dimensões", sob orientação da Profa. Dra. Ana Lúcia Pastore Schritzmeyer. Tem \\ interesse pelos seguintes temas: sistema criminal, loucura, medida de segurança, \\ documentos e tecnologias de poder. \\ Bolsista FAPESP. \\ https://orcid.org/0000-0002-4407-4285 \\ E-mail: saraviera@usp.br
}

\title{
Notas
}

1 Ao longo do texto farei referência à população carcerária desta penitenciária usando pronomes femininos e masculinos de forma a contemplar os sapatões, termo êmico para pessoas que se relacionam erótico-afetivamente com mulheres e são referidas e autorreferenciadas no masculino pela população carcerária. Todos os termos êmicos das/os interlocutoras/es serão apresentados em itálico.

2 Neste pavilhão são alocadas, em tese, pessoas em tratamento clínico ou psiquiátrico.

3 Castigo ou pote é como são chamadas as celas onde ficam isoladas de 10 a 30 dias pessoas que sofrem alguma sanção disciplinar interna.

4 Trânsito são celas onde ficam pessoas que estão de passagem pela unidade. Seguro são celas onde ficam isoladas pessoas que são rechaçadas do convívio social pelo resto da população carcerária.

5 Os nomes de todas/os as/os interlocutoras/es da pesquisa são fictícios.

6 Além das explicações de Jane sobre a feitura desse objeto, sua confecção pode ser facilmente observada em vídeos no Youtube, bem como no filme O Prisioneiro da Grade de Ferro, a partir de outros objetos semelhantes que desempenham a mesma função. 
7 Procedimento realizado pelo GIR que consiste em revistar as celas de todo o pavilhão em busca de materiais ilícitos.

8 O funcionamento e a atuação desses agentes serão explicitados adiante.

9 Expressão êmica para indicar problema, confusão.

10 Jane indicou uma nota de rodapé no título com os dizeres: "Inverídico e sarcástico título. A ironia social ao omiti-los".

11 Abertura no centro da porta das celas utilizada para entregar as refeições e se comunicar com o interior da cela.

12 Nesse período ocorriam as manifestações de rua tanto a favor como contra o impeachment da ex-presidenta Dilma Roussef.

13 Esta expressão advém dos estudos de Biondi (2014) acerca dos movimentos, ideias e situações que caracterizam a atuação do Primeiro Comando da Capital (PCC) entre cadeias e quebradas. A partir da fala de seus interlocutores, a autora sugere que as ideias que circulam e compõem o PCC só existem enquanto fluxo, cuja vida e movimento depende de sua constante repercussão e fortalecimento. "Basta que as ideias deixem de repercutir para que elas morram". Uma das formas disso ocorrer é quando "uma ideia lançada não é abraçada por ninguém, deixa de ser manifestada e, portanto, morre. [...] Também deixam de ser abraçadas as ideias que têm grande exterioridade em relação ao ritmo corrente e, por isso, não são capazes de se acoplar a ele" (:162). Reconheço o uso dessas expressões na penitenciária onde realizei o projeto, uma vez que esta se configura como domínio de atravessamento de ideias e movimentos que compõem o PCC. O fato de tanto Jane quanto eu não nos manifestarmos mais sobre o projeto de reescrever parte dos livros perdidos durante o tempo em que ela estaria no castigo fez com que a ideia morresse.

14 Ainda que tenha ressalvas quanto ao uso do termo "subalterno" - que poderia ser referido como "subalternizado", de modo a não fixar uma determinada condição ou identidade -, mantenho-o tal como propõe a autora. O termo faz referência às "camadas mais baixas da sociedade, constituídas pelos modos específicos de reclusão dos mercados, da representação política e legal, e da possibilidade de se tornarem membros plenos do estrato social dominante" (Spivak 2010b:12).

15 O trecho em que a autora coloca esta questão é o que segue: "she needed me only to read her, hear her, make her speak by default" (Spivak 2010b:230).

16 Levando em conta apenas os poemas escritos por Shaikh Abdurraheem Muslim Dost, detido naquele campo, cerca de 25 mil poemas foram confiscados e destruídos antes de chegarem às mãos de advogados e agentes de direitos humanos (Butler 2015:88).

17 A criação de nomes fictícios visa preservar a identidade das pessoas que participaram da pesquisa, uma vez que algumas ainda se encontram no sistema carcerário. 
18 A aplicação de medida disciplinar pelo isolamento nas celas do castigo pode, a depender da "gravidade" da falta disciplinar cometida, incidir sobre os benefícios previstos na progressão da pena, como "saidinhas" em datas comemorativas ou na transição da pena para o regime semiaberto. Acompanhei casos que, devido ao acúmulo de faltas disciplinares, incorreram no cumprimento da pena "de ponta", isto é, no período completo em regime fechado.

19 Nas descrições de Cordioli (2017), professor psiquiatra da UFRGS, Diazepam, Lorazepam, Clonazepam pertencem à classe dos benzodiazepínicos (BDZ), preferenciais para o tratamento de ansiedade e insônia, enquanto Fluoxetina e Paroxetina configuram-se como antidepressivos destinados especialmente aos "transtornos do pânico". Segundo o autor, "quase todos os BDZ têm propriedades farmacológicas semelhantes: todos eles possuem efeitos sedativos, ansiolíticos e hipnóticos. São ainda relaxantes musculares, anticonvulsivantes, produzem dependência e reações de abstinência" (:04). "Os BDZs causam sedação, fadiga, perdas de memória, sonolência, incoordenação motora, diminuição da atenção, da concentração e dos reflexos" [...] são muito utilizados em situações heterogêneas e não bem definidas, como na ansiedade situacional, em pacientes com instabilidade emocional, nervosismo, nas quais existe ansiedade aguda e crônica" (:06). Fluoxetina é indicado em casos de "depressão crônica" e paroxetina "quando há ansiedade" (:16).

20 A ocorrência de mortes no sistema penitenciário brasileiro em decorrência da negligência de atendimento médico é alarmante. Apenas no estado de São Paulo, no ano de 2014, a Secretaria de Administração Penitenciária (SAP) informou que dos 482 falecimentos nos presídios do estado, 450 decorreram de "morte natural". Outro censo publicado pelo Infopen (sistema de informações estatísticas do sistema penitenciário brasileiro) em 2017 mostra que, entre todos os óbitos registrados no primeiro semestre daquele ano, o maior índice provém de "óbitos naturais (óbitos por motivos de saúde)". De uma taxa total de 15,2 óbitos no sistema prisional para cada grupo de 10 mil pessoas presas, 8,4 decorreram de "causa natural".

21 As pesquisas de Angotti e Braga (2015), Matsuda (2016) e Mallart (2019) apontam para a existência de circuitos internos de pílulas psiquiátricas comercializadas entre as pessoas aprisionadas. No campo realizado na PFS pude observar recorrentes comentários sobre a compra ou a troca de psicotrópicos entre as/os presas/os.

22 Expressão recorrente entre a população carcerária para se referir aos Hospitais de Custódia e Tratamento Psiquiátrico (HCTP), para onde são encaminhadas pessoas em conflito com a lei consideradas inimputáveis por diagnóstico de transtorno mental. Em teoria, lá ficam as pessoas que cumprem "medida de segurança", que consiste numa medida de tratamento psiquiátrico compulsório, por tempo indeterminado, até que seja constatada a "cessação da periculosidade" por um perito psiquiatra. O trabalho de campo que realizei na PFS e que continuo a desenvolver em várias unidades prisionais do estado indica que, com frequência, pessoas com quadros psiquiátricos considerados "agudos" são levadas ao HCTP I de Franco da Rocha até terem seu "quadro estabilizado". Para mais informações sobre esses fluxos e o funcionamento dos HCTPs no estado de São Paulo, ver o relatório produzido pelo 
GT de Saúde Mental e Liberdade da Pastoral Carcerária, do qual faço parte (Pastoral Carcerária 2018) e a tese de Mallart (2019), na qual o autor aprofunda a discussão sobre os "subterrâneos" do arquipélago prisional-manicomial.

23 De acordo com o autor, a França apresentou, na última metade do século, aumento alarmante na taxa de suicídios no meio carcerário - avaliam ser hoje sete vezes maior do que a entre a população geral (Fassin 2015:90).

\section{Referências bibliográficas}

AGAMBEN, Giorgio. 2008. O que resta de Auschwitz: o arquivo e a testemunha (Homo sacer III). São Paulo: Boitempo.

DAS, Veena. 2007. Life and Words: Violence and the descent into the ordinary. Berkeley: University of California Press.

BERÁRD, Jean. \& CHANTRAINE, Gilles. 2008. "La carcéralisation du soin psychiatrique". Vacarme, n. 42:91-94. BIONDI, Karina. 2014. Etnografia no Movimento: Território, Hierarquia e Lei no PCC. Tese de Doutorado, Universidade Federal de São Carlos. BUTLER, Judith. 2015. Quadros de Guerra: quando a vida é passível de luto? $1^{\mathrm{a}}$ ed. Rio de Janeiro: Civilização Brasileira.

. 2018. Corpos em aliança e a política das ruas: notas para uma teoria performativa de assembleia. Trad. Fernanda Siqueira Miguens. Rio de Janeiro: Civilização Brasileira.

CORDIOLI, Aristides. V. 2017. "Psicofármacos nos transtornos mentais". Disponível em: http://www. ufrgs.br/psiquiatria/psiq/Caballo $\% 20$ 6_8.pdf. Acesso em 16/08/2020.

CSORDAS, Thomas. 2009. Corpo, Significado, Cura. Porto Alegre: Editora UFRGS.
FASSIN, Didier. 2015. "L'asile et la prison". Esprit, 3:82-95, mars-avril.

FOUCAULT, Michel. 2002 [1974-75]. Os anormais: curso no Collège de France. São Paulo: Martins Fontes. . 2007 [1975]. Vigiar e punir: nascimento da prisão. Petrópolis: Vozes. 2011 [1979. Microfísica do poder. Rio de Janeiro: Edições Graal.

GODÓI, Rafael. 2015. Fluxos em cadeia: as prisões em São Paulo na virada dos tempos. Tese de Doutorado, Faculdade de Filosofia Letras e Ciências Humanas, Universidade de São Paulo.

INGOLD, Tim. 2015. Estar Vivo: ensaios sobre movimento, conhecimento e descrição. Petrópolis, RJ: Vozes

KAFKA, Franz. 1998. O veredicto e $\mathrm{Na}$ colônia penal. São Paulo: Companhia das Letras.

LEVI, Primo. 2016. Os afogados e os sobreviventes. São Paulo/Rio de Janeiro: Paz \& Terra.

MACCLINTOCK, Anne. 2010. Couro Imperial: raça, gênero e sexualidade no embate colonial. Campinas, São Paulo: Editora Unicamp.

MALVENTI, Dario. 2009. Curar y reinsertar: líneas de fuga de la máquina penal contemporánea. Tese de Doutorado em Antropologia, Universidad de Barcelona. 
PASTORAL CARCERÁRIA. 2018. Hospitais-prisão: notas sobre os manicômios judiciários de São Paulo. São Paulo: Pastoral Carcerária da Arquidiocese de São Paulo.

REED, Adam. 2007. "Smuk is king: the action of cigarettes in a Papua New Guinea Prison". In: Amiria Henare et al., Thinking through things: theorizing artefacts ethnographically. London/New York: Routledge. pp. 391-406.

ROLNIK, Suely. 2003. "'Fale com ele' ou como tratar o corpo vibrátil em coma". In: Corpo, Arte e Clínica, UFRGS, Instituto de Psicologia, Programa de Pós-Graduação em Psicologia Social e Institucional, Porto Alegre.

ROSEIRA, Ana P. 2017. A porta da prisão: uma história dos meios de segurança e coerção penal na perspectiva dos guardas prisionais portugueses (19742014). Tese de Doutorado em História Contemporânea, Universidade de Coimbra.

RUSSO, Jane; VENANCIO, Ana Teresa A. 2006. "Classificando as pessoas e suas perturbações: a 'revolução terminológica' do DSM III". Rev. latinoam. psicopatol. fundam., São Paulo, v. 9, n. 3:460-483.

RUSSO, Jane. 2017. Do psíquico ao somático: notas sobre a reconfiguração do self contemporâneo. História, Ciências, Saúde - Manguinhos, Rio de Janeiro, v. 24, supl.:157-169.

SPIVAK, Gayatri C. 2010a. Pode o Subalterno Falar? Belo Horizonte: Editora UFMG. .2010b. "In response". In: Rosalind Morrison (org.), Can the Subaltern Speak? Reflections on the History of an Idea. Nova York: Columbia University Press.

TAETS, Adriana R. F. 2012. Abrindo e fechando celas: narrativas, experiências e identidades de agentes de segurança penitenciárias femininas. Dissertação de Mestrado, Faculdade de Filosofia Letras e Ciências Humanas. Universidade de São Paulo.

WACQUANT, Loic. 2007. "Os excluídos da sociedade de consumo: toxicodependentes, psicopatas e sem-abrigo nas prisões americanas". Análise Social, v. XLII, n. 185:9871003. 
RESSALTOS, ANESTESIAS E

FISSURAS: SOBRE A COSTURA COTIDIANA DE CORPOS APRISIONADOS

Resumo

A proposta do texto é apresentar e discutir táticas de resistências corporais acionadas por pessoas presas em uma penitenciária feminina no esforço cotidiano de viver na/à prisão. Posto que o confinamento serve a políticas governamentais de controle e gestão populacional, cujas disposições buscam cercear ou, no limite, exterminar as formas de vida daqueles aprisionados, o presente texto chama atenção para as táticas mobilizadas através do corpo para comportar a vida entre grades. Seja pela escrita, seja pela escarificação da pele, ou pela medicalização psiquiátrica, essas inscrições aparecem como táticas de resistência às tentativas de apagamento da pessoa aprisionada.

Palavras-chave: Prisão, Corpo, Resistência, Medicalização.
BUM PS, NUM BNESS AND FISSURES: ON THE DAILY STITCHING OF IMPRISONED BODIES

This article discusses the tactics of corporal resistance exerted by people imprisoned in a female penitentiary, in their daily efforts to live in prison. Since confinement serves government policies of population control and management, seeking to curtail, or, at the limit, exterminate the life forms of those imprisoned, the article draws attention to the tactics enacted through the body in order to conduct life behind bars. Whether through scarification of the skin or psychiatric medicalization, these bodily inscriptions appear as signs of resistance and ways to subvert the erasure and normalization of the imprisoned subject.

Keywords: Prison, Body, Resistance, Medication. 
RESALTOS, ANESTESIAS Y FISURAS:

SOBRE LA COSTURA COTIDIANA DE CUERPOS ENCARCELADOS

\section{Resumen}

El propósito del texto es presentar y discutir las tácticas de resistencia corporal desencadenadas por personas encarceladas en una penitenciaria femenina en el esfuerzo diario de vivir encarceladas. Dado que el confinamiento sirve a las políticas gubernamentales para el control y la gestión de la población, cuyas disposiciones buscan reducir o, al límite, exterminar las formas de vida de los encarcelados, este texto llama la atención sobre las tácticas movilizadas a través del cuerpo para acomodar la vida entre rejas. Ya sea por escrito, escarificando la piel o por medicalización psiquiátrica, estas inscripciones aparecen como tácticas de resistencia a los intentos de borrar a la persona encarcelada.

Palabras clave: Cárcel, Cuerpo, Resistencia, Medicalización. 